\title{
A Study of "Excellent Teachers" Training Program based on Normal University Students Majoring in Elementary Education--Taking Elementary Education Majors in Chongqing Municipality as an Example
}

\author{
Fang Chen", a , Li Zhu², b, Jiang Yao ${ }^{3, ~ c}$, Yu Chen ${ }^{4, d}$ \\ ${ }^{1}$ Chongqing normal University Chongqing 400700 China \\ ${ }^{2}$ Chongqing Electromechanical Vocational Institute Chongqing 402760 China \\ ${ }^{3}$ wuquan middle school, wangcang county, SiChuan 628213 China \\ ${ }^{4}$ Jiulongpo District of Chongqing Shixin Road Primary School Chongqing 400039 China \\ a49403591@qq.com, b17007811@qq.com, c251449416@qq.com, d986792775@qq.com
}

Keywords: Normal University Students; Excellent Teachers; Elementary Education.

\begin{abstract}
Excellent Teachers" Training Program is the basic path to "strengthening the nation through talents" and the basic requirements for improving the comprehensive quality and professional skills of the faculty. Based on the practice of Chongqing "Excellent Teachers" training structure and mode for elementary education, this paper analyzed the current status and problems in relation to "Excellent Teachers" training and aimed at optimizing and improving the training program by the method of segmenting training standards, breaking prejudice and motivating students to participate in this program more actively. As concerned with elementary school practice, professional skills of normal university students, and existing problems related to "Excellent Teachers" training, the study will help with exploration of a tailored training program for teaching practice and uplifting the horizon for future educational development.
\end{abstract}

\section{Introduction}

"Excellent Teachers" is the spirit of General Secretary Xi Jinping's important address on Teachers' Day, 2014, whose genre is to cultivate versatile teachers. Opinions of the Ministry of Education Concerning Implementation of "Excellent Teachers" Training Program [JS(2014)5] explicitly designated that normal university students were the major subject under this program. In order to promote the implementation of "Excellent Teachers" training program, internal and external resources around optimizing training structure and improving training initiatives and mechanism are being integrated from various universities and colleges to set up a "Trinity" collaborative cultivation platform, which will stably push forward sustainable development of the program for normal university students majoring in elementary education.

\section{Overview of Excellent Teachers Training Program}

2.1 What Are the Main Tasks "Excellent Teachers"?-Teaching Students Ethnic and Academic Knowledge as Well as Answering Their Questions to Save Them from Confusion

"Excellent" means extraordinary and outstanding. Excellent Teachers are extraordinarily outstanding teachers far more knowledgeable and learned than ordinary ones. Training excellent teachers is the demand and critical initiative for promoting educational reform and improving educational level comprehensively. It is an indispensable indicator for efficient education. The saying goes, "We have excellent officials in ancient times and we call for excellent teaches today". Excellent teachers are high-quality talents competent all round in morality, intelligence, physical fitness aesthetic sense and hard-working endurance. Thus the target of training program should involve cultivating versatile teachers conscious of their duties to forge students' soul and life. In brief, good teachers are just knowledge carriers and transmitters; excellent teachers are far more than that. They are not only 
passing on knowledge, but also enabling students to learn, understand and digest knowledge. They guide students to "put what they learn into use". Elementary education is the start point of compulsory education system in China, during which, ideological guidance is critical. Only those teachers with tangible knowledge base and enough care for students can give correct ethic guidance and help students set a solid foundation for future study.

\subsection{Interpretation of Excellent Teachers Training Program}

Excellent teachers Training Program is an indispensable plan of the Ministry of Education. It consists of 80 sub-projects for reforming excellent-teacher cultivation plan and designates a collaborative "trinity" cultivation mode by integrating universities, governments and middle/elementary schools. University enrollment is emphasized to better integrate educational resources (i.e. normal university students), and the enrollment screening process will be intensified in various forms, for example, enrollment autonomy, secondary screening and diversified entrance interviews. Training excellent teachers is an innovative initiative of educational reform, which does a favor to set up interlocking mechanism for training middle school and elementary school teachers by the way of establishing teaching and research institutions. The entire process should be careful and rigid. Universities are program executors responsible for selection and customized cultivation of excellent normal university students who can better serve for society. Most normal universities have already defined their own Excellent Teacher training programs, for example, Construction and Practice of Training Mode for Excellent Versatile Teachers proposed by Northeast Normal University (NNU) and UGIS-based Reform and Practice of Training Mode for Excellent Versatile Teachers from Chongqing Normal University. (CNU) [2].

\section{Excellent Teacher Training Framework and Mode for Elementary Education in Chongqing}

\subsection{A Collaborative "Trinity"-Universities, Governments and Middle/Elementary Schools}

The "Trinity" means a collaborative training mode by integrating universities, governments and middle/elementary schools. Universities are the executor of the training program. Under governmental support, the output of the program (i.e. excellent middle/elementary school teachers) is delivered into middle and elementary schools to accept teaching practice and tests. Such a collaborative training mode will access normal university students to directional, purpose-specific and well-organized training from enrollment. After accepting the training, graduates will give full play to their "Excellent" skills in teaching practice and provide better service for society. The 80 Excellent Teacher training sub-projects listed by the Ministry of Education have covered 62 universities around the country. With full support from various levels of educational institutions, a top-to-bottom training mode has been established. The "Trinity" we mentioned above is a powerful drive for employment of normal university students, and an effective lever to harmonize unequal distribution of educational resources and optimize resource allocation. Moreover, the "Trinity:" serves as a mutually complementary platform for resources exchange and sharing among normal university students. High-quality graduates are encouraged to flow into rural areas, driving a balanced development of our educational cause. The collaboration among universities, governments and (middle/elementary) schools (i.e. the Trinity)not only ensures optimal allocation of educational resources, but also create a favorable employment environment for normal university graduates.

\subsection{Systematic Cultivation of "Versatile Teachers"-Moral, Intellectual, Physical, Aesthetic and Hard-Working All-Round Development}

Along with the deepening of educational reform, the duties and requirements on teachers are increasingly demanding. Teachers are no longer purely knowledge transmitters. They are "guides" responsible not only for teaching students how to learn, but also guiding them how to use what they learn. The role-transition requires consequent adjustment of teacher training mode. Excellent Teachers training program is an experimental reform starting with cultivation of faculty and targeting at improving teachers' quality. CNY's Excellent Teacher training project is based on the topic of training 
versatile elementary school teachers. Around basic requirements of syllabus, various universities in Chongqing are highly concerned with "individualization" in their practice of training normal university students. A complete set of teaching assessment system is established to supervise students' study at times. Sessions and experience exchanges are held to enrich students' routine life. Senior instructors are hired to share their skills so as to expand horizon and direction of normal university students. The key to versatile teachers is "all-round development", which highlights teacher's comprehensive competence and requires teachers to squeeze out all that they learn during the teaching process. Cultivation of versatile teachers is the basic requirement for quality education and the major tendency for future faculty training.

\section{Problems related to training Excellent Teachers among normal university students majoring in elementary education.}

\section{1 "Ambiguous" Standards on Training}

The target of Excellent Teachers training program is to cultivate comprehensive professional talents. A set of unified standards is the precondition for fulfilling the objective and break through limitations. However, ambiguous standards are universal among various universities. For example, uncertainties are found everywhere: how to define "Excellent Teachers"? How to make enrollment plan? What are the curriculum standards and proficiency standards? A series of standards on curriculum and proficiency have been issued by the Ministry of Education, though, all those are tailored for "Qualified teachers" rather than "Excellent Teachers". A lack of distinction of Excellent Teachers from Qualified Teachers will diverge the training program from its target. In addition, a series of supplementary standards have been worked out by most universities around the "Excellent Teacher training Program", but they are more theoretic than practical, giving little force to push the program forward.

\subsection{Inferiority of Teaching Practice to Academic Research}

There is imbalance between academic research and teaching practice during the process of faculty training. Training Excellent Teachers is a process of combining theories with practice and yet during early stage, universities incline to cram more theories to students for purpose of giving better guidance to practice. Such inferiority of teaching practice to academic research also diverge the program from its basic requirements. Teachers serve as important participants and guides in teaching practice. They must fully understand the meaning of "Excellency" and manage to enrich their own skills around the program so that an effective bi-directional training mechanism can work. Education is a progressive way. Purely arming students with theories may wear out their study interests, and inactivate long-term efficient study. In the recent Opinions of the Ministry of Education Concerning Promotion of Educational Curriculum Reform, the spirit of "Excellent Teachers Training Program" is highly emphasized, but the introduction to syllabus and training strategy are rarely seen. There are no rules or reasons for universities to obey during cultivating normal students. Not a few "armchair critics" may occur due to the weakness in professional practicing.

\subsection{Poor Consciousness of Participation Among Students}

Excellent Teachers training is a training plan for cultivating high-quality and professional talents tailored for normal university students. Normal university students are the subjects and participants. However, for a lack of basic promotion and guidance, few normal university students have basic awareness of "Excellent Teachers Training Program". In fact, to be a participant in the program is a honorable cause. It's pitiful that students fail to distinguish "excellent" from "qualified and some even equate "Excellent Teachers Training" with routine study. "Excellency" is hard to reach owing to such poor consciousness of participation. Training excellent teachers is a process of selecting talents and a process of survival the fittest. Only by realizing the current employment tension and the importance of ability training, can normal university students become a more active learner who can better adapt themselves to society. Therefore, poor consciousness and laziness in participation are big barriers to sustainable development of this program. 


\section{Reflection over feasible strategies of Excellent Teachers Training Program for normal university students majoring in elementary education}

\subsection{Segmentation of Training Standards}

Opinions of the Ministry of Education Concerning Implementation of "Excellent Teachers" Training Program specifies to further optimize and implement the standards on training Excellent Teachers, for example, specific enrollment standards, equal and fair selection conditions, transparent training procedures, practical training measures, by which a highly efficient and risk-free cultivation mode can be construed by various universities during the process of training professional normal students majoring in elementary education. Meanwhile, segmented standards and simplified training procedures are helpful for expanding disciplinary construction. Considering the multiple disciplines of elementary education major, segmented standards ensured customized and professional cultivation, giving great incentive to improving the professional competence of faculty.

\subsection{Breaking Prejudice}

Inferiority of teaching practice to academic research is an undesirable prejudice. The present qualification examination on teachers is related to pedagogy, psychology and teaching methodology. Factually, education is a comprehensive learning process. Teachers are "almighty" in students' mind. Especially in elementary education, students are highly reliant on teachers. Except books, teachers should enrich students' horizon with a large quantity of extracurricular knowledge. In addition, only those who treat students "individually" and teach them "how to use what they learn" can quaint the pupil's thirst for knowledge. Therefore, in an Excellent Teachers Training Program, we need to break prejudice and create a sharing training mode by integration of teaching with studying, theory with practice, and individuals with community. Only when normal university graduates can convert theories into practice based on what they learn, can we expect high efficient utilization of resources be reasonably achieved in future.

\subsection{Motivating Students to Participate Actively}

Active participation is the drive force to lift initiatives and interests. All universities should strengthen promotion of this program and motivating normal university students to participate, for example, innovative enrollment mode, optimized structure of enrollment, or improved enrollment quality. All those will effectively expand the range of selection. Meanwhile, to strike a balance between male teachers and female teachers, the sex ratio should be properly adjusted during enrollment. To enroll students suited to different majors, a combined entrance examination mechanism integrating "college entrance examination, general examination and in-school examination can be used to enroll excellent students by ranking at a reasonable ratio so as to select out and reserve high-quality students. In addition, relevant incentives, such as tuition exemption, scholarship, employment assurance, may be offered to encourage students to actively participate in this program until a dynamic and vigorous cycle is fully formed.

\section{Conclusion}

The study of Excellent Teachers Training Program based on Chongqing's normal university students majoring in elementary education made a profound analysis of the current status, planning and strategies of cultivating elementary school teachers from a practical perspective. The study of "Excellent Teachers" training program provides theoretic foundation for training versatile teachers by universities, efficiently improving teachers' proficiencies and enhances high-quality faculty construction. The reflection over feasible strategies is of great value for realizing conversion and utilization of education resources. 


\section{Acknowledgments}

General foundation project of Chongqing Research Center of Children Development and Teacher Training: cultivation of excellent teachers majoring in elementary education: a study of professional skill training based on the developing normal university students (JSJY1605)

\section{References}

[1]. runqing Gao .Practice and exploration of the "three in one" cooperative training mode of excellent teachers[J]. Curriculum, Teaching Material and Method.2015(07)

[2]. Shujuan Yu.The main international experience of the development of the general education of excellent teachers in primary schools[J].Educational Science Research.2015(12)

[3]. xiangmin Zhang. A comparative study on the maturity and difference of the professional attitude of the graduates from normal universities -- a case study of a normal university[J].Continuing education research.2012(11)

[4]. songxiang Zhang. A study on the problems and Countermeasures of the training of teachers in general schools[J].Education Development Research.2015(Z2) 